\title{
Publisher Correction: CD146-HIF-1 $\alpha$ hypoxic reprogramming drives vascular remodeling and pulmonary arterial hypertension
}

\author{
Yongting Luo (1) ${ }^{1}$, Xiao Teng ${ }^{2}$, Lingling Zhang ${ }^{3}$, Jianan Chen ${ }^{4}$, Zheng Liư ${ }^{4}$, Xuehui Chen ${ }^{4}$, Shuai Zhao ${ }^{4}$, Sai Yang $^{5}$,
} Jing Feng ${ }^{4} \&$ Xiyun Yan ${ }^{4}$

Correction to: Nature Communications https://doi.org/10.1038/s41467-019-11500-6, published online 7 August 2019.

The original HTML version of this Article contained errors in Figures 6 and 7. Figures 6 and 7 were inadvertently replaced by incorrect figures. This has been corrected in the HTML version of the Article.

Published online: 05 September 2019

\begin{abstract}
(c) (i) Open Access This article is licensed under a Creative Commons Attribution 4.0 International License, which permits use, sharing, adaptation, distribution and reproduction in any medium or format, as long as you give appropriate credit to the original author(s) and the source, provide a link to the Creative Commons license, and indicate if changes were made. The images or other third party material in this article are included in the article's Creative Commons license, unless indicated otherwise in a credit line to the material. If material is not included in the article's Creative Commons license and your intended use is not permitted by statutory regulation or exceeds the permitted use, you will need to obtain permission directly from the copyright holder. To view a copy of this license, visit http://creativecommons.org/licenses/by/4.0/.
\end{abstract}

(C) The Author(s) 2019

\footnotetext{
${ }^{1}$ Beijing Advanced Innovation Center for Food Nutrition and Human Health, China Agricultural University, Yuanmingyuan West Road 2, 100193 Beijing, China. ${ }^{2}$ State Key Laboratory of Cardiovascular Diseases, Fuwai Hospital, National Center for Cardiovascular Diseases, Chinese Academy of Medical Sciences and Peking Union Medical College, No. 167 North Lishi Road, 100037 Beijing, China. ${ }^{3}$ Department of Rheumatology and Clinical Immunology, Peking Union Medical College Hospital, Chinese Academy of Medical Sciences \& Peking Union Medical College, No. 1 Shuaifuyuan, 100730 Beijing, China. ${ }^{4}$ Key Laboratory of Protein and Peptide Pharmaceutical, Institute of Biophysics, Chinese Academy of Sciences, 15 Datun Road, 100101 Beijing, China. ${ }^{5}$ Laboratory Animal Research Center, Institute of Biophysics, Chinese Academy of Sciences, 15 Datun Road, 100101 Beijing, China. Correspondence and requests for materials should be addressed to Y.L. (email: luo_yongting@163.com) or to X.Y. (email: yanxy@ibp.ac.cn)
} 